\title{
HLA-DR phenotypes in Spanish coeliac children: their contribution to the understanding of the genetics of the disease
}

\author{
M L MEARIN, I BIEMOND, A S PEÑA, I POLANCO, C VAZQUEZ, \\ G TH M SCHREUDER, R R P DE VRIES, AND J J VAN ROOD
}

From the Department of Gastroenterology, University Medical Centre, Leiden, The Netherlands, the Department of Gastroenterology, La Paz Children's Hospital, Madrid, Spain, and the Department of Immunohaematology, University Medical Centre, Leiden, The Netherlands

SUmmarY The DR-locus controlled B-cell antigens were studied in 163 unrelated Spanish coeliac children and 68 families of this group, nine of them with more than one coeliac patient, to obtain more information about the association between these antigens and coeliac disease. The results show that the most common coeliac phenotypes are DR3/DR7, DR7/DR5, DR3/other DR, and DR3/DR3. The family study confirmed the segregation of the disease with the above mentioned phenotypes. In eight of the nine multiple case families, all coeliac children shared both HLA-DR antigens. These findings make it unlikely that a single dominant gene linked to HLA-DR controls the susceptibility to coeliac disease. The phenotypes in the patients were not distributed according to the Hardy-Weinberg equilibrium. Thus, a model based on one recessive susceptibility gene linked to HLA-DR is not probable either. The complexity of the genetics of coeliac disease and some of the features shared with the HLA-DR pattern in juvenile insulin-dependent diabetes are discussed.

Coeliac disease is known to have a hereditary character, but the mode of inheritance is still obscure. Extensive studies have shown an association between coeliac disease and HLA-B8, 12 and a still stronger one with HLA-DW3 ${ }^{3}$ and HLA-DR3. ${ }^{4-6}$ It is also known that HLA-DR3 is not a specific marker for this disease. An association exists also with HLA-DR7. ${ }^{7-11}$ Some authors have reported an excess of the HLA-DR genotypes DR3/DR7, DR3/DR3, and DR3/other DR. ${ }^{8-11}$

We have studied the DR locus-controlled B-cell antigens in Spanish coeliac children and their families to obtain more information about the association between these antigens and coeliac disease.

\section{Methods}

\section{PATIENTS}

A series of 163 unrelated Spanish coeliac children (99 girls and 64 boys; mean age eight years) and all

Address for correspondence: Dr A S Peña, Department of Gastroenterology, University Medical Centre, Rijnsburgerweg 10, 2333 AA Leiden, The Netherlands.

Received for publication 27 August 1982 first degree relatives of 68 of them were typed for the HLA-DR specificities. In all cases the diagnosis of coeliac disease was made in the Gastroenterology Unit of the La Paz Children's Hospital in Madrid according to the ESPGAN criteria. ${ }^{12}$ Nine of the 68 families had two or more children affected by coeliac disease.

\section{CONTROLS}

A group of 76 unrelated healthy Spanish volunteers served as the controls. All of them were typed for the known HLA-DR specificities.

\section{HLA-DR LOCUS TYPING}

Blood samples were taken in Madrid and flown to Amsterdam on the day of collection. HLA-DR typing was performed by the two colour fluorescence test ${ }^{13}$ with a set of 60 platelet absorbed sera. The specificities HLA-DR 1, 2, 3, 4, 5, w6, 7, w8 and w9 could be recognised.

\section{Results}

POPULATION STUDY

The distribution of the HLA-DR locus specificities 
in patients and controls is shown in Table 1 . In the control group, the distribution of the HLA-DR antigens is in Hardy Weinberg equilibrium and the gene frequencies do not differ from those found in 181 healthy controls in Spain. ${ }^{14}$ When the frequency of DRw6 was taken together with that given for DR6y in the above mentioned report, there was no divergence from the DRw6 frequency in our control group. A significant positive association between coeliac disease and HLA-DR3 and HLA-DR7 antigens is evident in Table 1 , the relative risk for coeliac disease being 11.5 and 2.6 respectively. Table 2 shows that in this series by far the most common coeliac phenotype is DR3/DR7, followed by, in decreasing order, DR7/DR5, DR3/other DR, and DR3/undetermined. The notation undetermined is used for cases where no other DR-antigen was detected. The phenotypes DR3/DR7, DR7/ DR5, and DR3/undetermined account for $68.7 \%$ of the patients studied versus $7.9 \%$ in the controls. Comparison between the frequencies of the phenotypes, in the coeliac disease and control group showed that these three phenotypes, namely DR3/ undetermined, DR3/DR7, and DR7/DR5, are positively associated with coeliac disease. After correction for the number of comparisons, only the association with DR3/DR7 and DR3/undetermined proved to be statistically significant. It is interesting to note that $98 \%$ of the coeliac patients have one of the antigens DR3, DR7 or DR5.

\section{FAMILY STUDY}

The HLA-DR-genotype distribution of the 68 studied families are presented in Table 3.

In 31 of the 68 families, only one of the parents is heterozygous for HLA-DR3. In these families, 27 of

Table $1 \quad H L A-D R$ antigen frequency distribution in 163 Spanish children with coeliac disease and 76 Spanish controls

\begin{tabular}{|c|c|c|c|c|c|}
\hline$H L A-D R$ antigens & & $\begin{array}{l}\text { tients } \\
=163) \\
\%\end{array}$ & $\begin{array}{c}\text { Controls } \\
(N=76) \\
+\quad \%\end{array}$ & $\begin{array}{l}\text { Significance } \\
\text { (p value })^{*}\end{array}$ & $\begin{array}{l}\text { Relative } \\
\text { riskt }\end{array}$ \\
\hline DR1 & 4 & 2.45 & $1519 \cdot 74$ & $2 \cdot 10^{-4}$ & 0.11 \\
\hline DR2 & 3 & 1.84 & 2228.95 & $9 \cdot 10^{-9}$ & 0.05 \\
\hline DR3 & 116 & $71 \cdot 17$ & $1317 \cdot 10$ & $2 \cdot 10^{-13}$ & $11 \cdot 54$ \\
\hline DR4 & 20 & $12 \cdot 26$ & $1519 \cdot 73$ & ns & 0.57 \\
\hline DR5 & 47 & 28.83 & $22 \quad 28.95$ & ns & 0.99 \\
\hline DRw6 & 8 & 4.91 & $22 \quad 28.95$ & $6 \cdot 10^{-6}$ & 0.13 \\
\hline DR7 & 100 & $61 \cdot 35$ & $2938 \cdot 16$ & $8 \cdot 10^{-3}$ & $2 \cdot 55$ \\
\hline DRw8 & 2 & 1.23 & $\begin{array}{ll}3 & 3.95\end{array}$ & ns & 0.33 \\
\hline DRw9 & 1 & 0.62 & $0 \quad 0.00$ & ns & 1.41 \\
\hline
\end{tabular}

* Two-tailed p value corrected for number of antigens, calculated according to R A Fisher's chi-square, Yates corrected. + According to Woolf, with Haldane's continuity correction. ns $=$ not significant .
Table $2 H L A-D R$ phenotype distribution in coeliac patients and controls

\begin{tabular}{|c|c|c|c|c|c|c|}
\hline \multirow[b]{2}{*}{$H L A-D R$} & \multicolumn{2}{|c|}{$\begin{array}{l}\text { Patients } \\
(N=163)\end{array}$} & \multicolumn{2}{|c|}{$\begin{array}{l}\text { Controls } \\
(N=76)\end{array}$} & \multirow{2}{*}{$\begin{array}{l}\text { Significance* } \\
p\end{array}$} & \multirow{2}{*}{$\begin{array}{l}\text { Relative } \\
\text { riskt }\end{array}$} \\
\hline & + & $\%$ & + & $\%$ & & \\
\hline DR3/undetermined & 20 & $12 \cdot 27$ & 0 & 0.00 & $4 \cdot 10^{-2}$ & $21 \cdot 8$ \\
\hline DR3/DR5 & 12 & $7 \cdot 36$ & 4 & $5 \cdot 25$ & ns & 1.4 \\
\hline DR3/DR7 & 62 & $38 \cdot 03$ & 2 & $2 \cdot 63$ & $2 \cdot 10^{-7}$ & $11 \cdot 5$ \\
\hline DR3/other & 22 & 13.43 & 7 & $9 \cdot 21$ & ns & $1 \cdot 5$ \\
\hline DR5/undetermined & 0 & 0.00 & 1 & $1 \cdot 32$ & ns & 0.2 \\
\hline DR5/DR7 & 30 & $18 \cdot 40$ & 4 & $5 \cdot 56$ & ns & $3 \cdot 7$ \\
\hline DR5/other & 5 & 3.06 & 13 & $17 \cdot 10$ & $4 \cdot 10^{-3}$ & $0 \cdot 2$ \\
\hline DR7/undetermined & 2 & $1 \cdot 23$ & 4 & $5 \cdot 26$ & ns & 0.2 \\
\hline DR7/other & 6 & 3.69 & 19 & $25 \cdot 00$ & $2 \cdot 10^{-5}$ & $0 \cdot 1$ \\
\hline other/other & 4 & $2 \cdot 45$ & 22 & 28.95 & $4 \cdot 10^{-8}$ & $0 \cdot 1$ \\
\hline
\end{tabular}

* Two-sided $\mathrm{p}$ value corrected for the number of comparisons (10) calculated according to chi-square, Yates corrected.

† According to Woolf, with Haldane's continuity correction. ns $=$ not significant.

The number of comparisons was 10 because of the nine phenotypes with either DR3 and/or DR5, and/or DR7 accounting for $97.5 \%$ among the patients. The other phenotypes $(2.45 \%)$ were compound.

the 31 coeliac children have the HLA-DR3 antigen, whereas in the group of healthy siblings the numbers of children with and without this antigen are distributed as would be expected according to the Mendelian segregation. A similar analysis for HLADR7 showed that in 27 families one of the parents is heterozygous for this antigen. Here, 22 of the 27 coeliac children have the HLA-DR7 antigen. In the healthy siblings the HLA-DR7 antigen shows a Mendelian distribution. Table 4 gives the segregation of the genotypes HLA-DR3/HLA-DR7 in 14 families with one parent heterozygous for HLA-DR3 and the other for HLA-DR7. The genotype HLA-DR3/HLA-DR7 is present in nine of the 14 coeliac children but in only six of their 29 healthy siblings, who show the expected distribution of the four possible HLA-DR genotypes. A similar analysis for genotype HLA-DR7/HLA-DR5 in five families where one of the parents is heterozygous for HLA-DR7 and the other for HLA-DR5 is also shown in Table 4. The genotype HLA-DR7/HLADR5 is present in four of the five coeliac children. Furthermore, in seven families where HLA-DR7 is present and HLA-DR3 is not, ail of the coeliac children have the DR7/DR5 genotypes (Table 3). The nine families with more than one case were excluded from this segregation study.

MULTIPLE-CASE FAMILY STUDY

Among the nine families with more than one coeliac child, two have two identical pairs of twins concordant for coeliac disease who were excluded from the study. Table 3 shows that the remaining 
Table 3 Segregation of HLA-DR antigens in 68 Spanish families with coeliac disease

\begin{tabular}{|c|c|c|c|c|}
\hline \multirow[b]{2}{*}{$\begin{array}{l}\text { Family } \\
\text { no }\end{array}$} & \multicolumn{4}{|c|}{ DR-genotype } \\
\hline & Father & Mother & $\begin{array}{l}\text { Coeliac } \\
\text { children }\end{array}$ & $\begin{array}{l}\text { Healthy } \\
\text { children }\end{array}$ \\
\hline 1 & 7.w8 & 3.w6 & 7.3 & 7.w6 \\
\hline 2 & 3.4 & 7.w6 & 3.w6 & 3.w6; 4.w6 \\
\hline 3 & 7.1 & $3.3 \ddagger$ & 7.3 & $1.3 ; 7.3$ \\
\hline 4 & 4.5 & 3.7 & 5.7 & $4.3 ; 5.3$ \\
\hline 5 & 7.2 & 3.w6 & $7.3+$ & $\begin{array}{l}2 . w 6 ; 7 . w 6 ; 2.3 \\
2.3 ; 2 . w 6 ; 7.3\end{array}$ \\
\hline 6 & 3.1 & 7.7 & 3.7 & 3.7 \\
\hline 7 & 4.2 & 5.5 & 4.5 & \\
\hline 8 & $3.3 \ddagger$ & 3.w6 & 3.3 & 3.w6 \\
\hline 9 & 3.5 & 7.7 & 5.7 & $3.7 ; 3.7$ \\
\hline 10 & 3.5 & 7.5 & 5.7 & 5.5 \\
\hline 11 & 7.1 & 3.4 & 7.3 & $1.3: 1.3 ; 1.4$ \\
\hline 12 & 3.3 & 7.1 & 3.7 & 3.7 \\
\hline 13 & 3.5 & 3.4 & 5.3 & 3.3 \\
\hline 14 & 3.4 & 3.4 & 3.3 & 4.4 \\
\hline 15 & 3.2 & 7.2 & 3.7 & $2.2 ; 2.2$ \\
\hline 16 & 4.w6 & 5.2 & 4.5 & w6. $2 ; 4.5$ \\
\hline 17 & 7.5 & 5.5 & 7.5 & $5.5 ; 7.5 ; 7.5$ \\
\hline 18 & 7.4 & 3.4 & 4.3 & $3.7: 3.7$ \\
\hline 19 & 3.1 & $3.3 \ddagger$ & 3.3 & 3.3 \\
\hline 20 & 7.5 & 3.2 & $7.3: 7.3$ & $7.2 ; 7.3$ \\
\hline 21 & 7.2 & 3.4 & 7.3 & $2.4 ; 2.3 ; 2.3$ \\
\hline 22 & 5.4 & 7.4 & $5.7: 5.7$ & \\
\hline 23 & 7.w6 & 5.1 & 7.5 & 7.5 \\
\hline 24 & 3.7 & 3.5 & $7.3 ; 7.3 ; 7.3$ & 7.5 \\
\hline 25 & 3.2 & 1.w6 & $3.1^{*}$ & 3.1;2.w6 \\
\hline 26 & 3.7 & 7.4 & 3.7 & 7.4 \\
\hline 27 & 3.3 & 3.4 & $3.3 ; 3.3$ & $3.4: 3.4: 3.4$ \\
\hline 28 & 4.4 & 3.1 & 4.3 & 4.3 \\
\hline 29 & 5.5 & 3.1 & 5.3 & 5.3 \\
\hline 30 & 3.1 & 3.4 & $3.3+$ & $3.3 ; 1.3$ \\
\hline 31 & 2.2 & 3.3 & $2.3 ; 2.3$ & 2.3 \\
\hline 32 & 3.5 & 7.7 & 3.7 & $\begin{array}{l}5.7: 5.7: 3.7 \\
5.7\end{array}$ \\
\hline 33 & 7.5 & 7.5 & 7.5 & $7.7: 7.5$ \\
\hline 34 & 3.5 & 7.w6 & 3.7 & 5.w6 \\
\hline 35 & 3.2 & $7.7 \ddagger$ & 3.7 & \\
\hline 36 & 7.4 & 3.4 & 7.3 & $4.4: 7.3$ \\
\hline 37 & 3.w6 & 5.w8 & 3.5 & \\
\hline
\end{tabular}

\begin{tabular}{|c|c|c|c|c|}
\hline \multirow[b]{2}{*}{$\begin{array}{l}\text { Family } \\
\text { no }\end{array}$} & \multicolumn{4}{|c|}{ DR-genotype } \\
\hline & Father & Mother & $\begin{array}{l}\text { Coeliac } \\
\text { children }\end{array}$ & $\begin{array}{l}\text { Healthy } \\
\text { children }\end{array}$ \\
\hline 38 & 7.4 & 5.3 & $7.5 ; 7.3$ & \\
\hline 39 & 3.5 & 7.1 & 5.7 & 3.1 \\
\hline 40 & 3.2 & 2.5 & 3.5 & 2.2 \\
\hline 41 & 3.1 & 3.7 & 3.3 & 1.3 \\
\hline 42 & 5.1 & 4.5 & 4.5 & $1.4 ; 5.5$ \\
\hline 43 & 3.5 & $7.7 \ddagger$ & 7.3 & 5.7 \\
\hline 44 & w6.w6 & w8.w6 & w6.w6 & w6.w6 \\
\hline 45 & $3.3 \ddagger$ & 3.2 & $3 . j$ & 3.3 \\
\hline 46 & $7.5^{\circ}$ & w6.5 & 7.5 & \\
\hline 47 & 7.2 & 3.w6 & 7.3 & $7.3 ; 2.3 ; 7.3$ \\
\hline 48 & 3.7 & 3.7 & 3.3 & 3.3 \\
\hline 49 & 1.2 & 3.5 & 1.3 & 5.2 \\
\hline 50 & 5.w6 & 7.w6 & 5.7 & w6.7 \\
\hline 51 & 3.2 & 4.4 & 3.4 & 3.4 \\
\hline 52 & 3.7 & $3.3 \ddagger$ & 3.3 & 3.3 \\
\hline 53 & 3.2 & 7.w8 & 3.w8 & 3.w8 \\
\hline 54 & 3.4 & w6.5 & 3.w6 & 4.5 \\
\hline 55 & 7.5 & 3.3 & 7.3 & $7.3 ; 7.3$ \\
\hline 56 & $3.3 \ddagger$ & 7.w6 & 3.7 & \\
\hline 57 & 3.w8 & 3.w6 & 3.3 & w8.3 \\
\hline 58 & 3.7 & 3.w10 & 7.3 & 7.w10 \\
\hline 59 & w6.1 & 3.5 & w6.3 & 1.5 \\
\hline 60 & $5.5 \ddagger$ & 7.5 & 5.7 & 5.7 \\
\hline 61 & 7.2 & 3.w6 & 7.3 & 7.w6 \\
\hline 62 & 3.7 & 7.1 & 3.7 & 7.1 \\
\hline 63 & $3.3 \ddagger$ & $7.7 \ddagger$ & 3.7 & 3.7 \\
\hline 64 & 3.7 & 7.4 & 3.7 & 7.7 \\
\hline 65 & 3.5 & 3.5 & 3.3 & 3.5 \\
\hline 66 & 3.3 & 7.1 & $3.7 ; 3.7$ & \\
\hline 67 & $7.7 \ddagger$ & 1.5 & 7.5 & $7.1 ; 7.1$ \\
\hline 68 & $3.3 \ddagger$ & $7.7 \ddagger$ & $3.7^{*}$ & 3.7 \\
\hline
\end{tabular}

* Monozygotic twins concordant for coeliac disease. Only one individual is included in the Table.

+ Monozygotic twins discordant for coeliac disease.

$\ddagger$ Presumed homozygotes. DR-genotypes of parents are determined according to the four complete HLA-haplotypes in a family.

seven families comprise one family where both coeliac children are homozygous for DR3 (family 27) one where both coeliac children are heterozygous for DR3/DR2 (family 31) three families where all of the coeliac children are heterozygous for DR3/DR7 (nos 20, 24, 66), and one family where both coeliacs are heterozygous for DR7/DR5 (family 22). In one family (38) one of the coeliac children is heterozygous for DR7/DR5 and the other for DR3/DR7.

\section{CALCULATION OF THE EXPECTED NUMBER OF DR PHENOTYPES}

We calculated the expected numbers of DR phenotypes in our coeliac population from its gene frequencies as derived from the observed

phenotypes according to the Hardy Weinberg equilibrium, assuming a recessive susceptibility gene, and compared the results with the observed phenotype frequencies (Table 5).

\section{Discussion}

Ten years have passed since the discovery of the association between coeliac disease and the HLAB8 antigen. ${ }^{12}$ Later it was shown that the disease is primarily associated with DW $3,{ }^{3}$ and HLA-DR3. ${ }^{4-7}$ Albert $e t a l^{7}$ were the first to observe that another antigen, namely DR7, was also associated with the disease, and these authors found an unexpectedly high number of heterozygous DR3/DR7. These findings were confirmed by DeMarchi et al. ${ }^{8}$ The 
Table 4 Segregation analysis of genotypes HLA-DR3/ $H L A-D R 7$ and HLA-DR7/HLA-DR5 in Spanish coeliac families

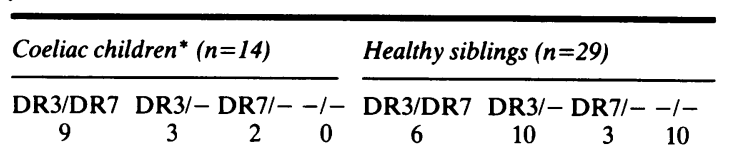

Coeliac childrent $(n=5)$

Healthy siblings $(n=6)$

DR7/DR5 DR7/+DR5/+ +/+ DR7/DR5 DR7/+DR5/+ + /+

\begin{tabular}{cccccccc}
4 & 1 & 0 & 0 & 1 & 1 & 2 & 2 \\
\hline
\end{tabular}

- = other antigen differing from HLA-DR3 or HLA-DR7.

$+=$ other antigen differing from HLA-DR7 or HLA-DR5.

* in 14 families with one parent heterozygous for HLA-DR3 and the other for HLA-DR7.

+ in five families with one parent heterozygous for HLA-DR7 and the other for HLA-DR5.

present population study confirms the association of the disease with DR3 and DR7 and shows for the first time an increase in heterozygosity for DR7/ DR5.

Our family study confirmed the segregation of the disease with HLA-DR3 and HLA-DR7 as well as with genotypes DR3/DR7 and DR7/DR5 (Table 4), and the present multiple case family study has shown that among six pairs and one family with three coeliacs, seven affected siblings are identical

Table 5 Expected and observed numbers of $D R$ phenotypes in 163 coeliac patients

\begin{tabular}{|c|c|c|c|}
\hline \multirow[b]{2}{*}{ DR phenotypes } & \multicolumn{3}{|c|}{ Gene frequencies* } \\
\hline & Observed & Expected & $\chi^{2}$ \\
\hline $\begin{array}{l}\text { DR3/DR3 } \\
\text { DR3/undetermined }\end{array}$ & $\begin{array}{l}(11) \dagger 20 \\
(9)\end{array}$ & $28 \cdot 37$ & $2 \cdot 47$ \\
\hline DR3/DR5 & 12 & $19 \cdot 61$ & 2.95 \\
\hline DR3/DR7 & 62 & $42 \cdot 55$ & $8 \cdot 89$ \\
\hline DR3/other $\ddagger$ & 22 & $17 \cdot 10$ & $1 \cdot 40$ \\
\hline DR5/undetermined & 0 & $3 \cdot 39$ & $3 \cdot 39$ \\
\hline DR5/DR7 & 30 & $14 \cdot 71$ & $15 \cdot 91$ \\
\hline DR5/other & 5 & $5 \cdot 91$ & $0 \cdot 14$ \\
\hline DR7/undetermined & 2 & $15 \cdot 96$ & $12 \cdot 21$ \\
\hline DR7/other & 6 & $12 \cdot 83$ & $3 \cdot 63$ \\
\hline other/other & 4 & $2 \cdot 58$ & 0.78 \\
\hline
\end{tabular}

$\chi^{2}=51 \cdot 77 ; \mathrm{df}=5 ; \mathrm{p}<0.001$.

DR3: $[(2 \times 20)+96](2 \times 163)=0.4172$.

DR5: $47(2 \times 163)=0 \cdot 1442$.

DR7: $[(2 \times 2)+98](2 \times 163)=0 \cdot 3129$.

other DR: $[(2 \times 4)+33](2 \times 163)=0 \cdot 1258$.

undetermined $=$ parents not typed; no other antigen detected. df $=$ degrees of freedom.

* blank alleles, whose gene frequency was $<0 \cdot 02$, were omitted from the calculations.

† the frequency for DR3/DR3 was confirmed by family study.

$\ddagger$ other antigen detected to the propositus with respect to the HLA-DR region. There is also one pair that does not share both antigens (Table 3 , family 38 ), but in this family we can assume, on the basis of our present population and family data, that the different antigen inherited by the affected sibling is associated with the same susceptibility gene. In view of the segregation of coeliac disease in the families where the majority of the affected siblings share both HLA-DR antigens (Table 3 ), it seems very unlikely that a single dominant gene linked to HLA controls susceptibility to coeliac disease.

Greenberg et al ${ }^{15}$ recently analysed and computed the published population HLA-DR data in coeliac disease. These authors used two models to compare the expected and observed phenotypes frequencies of DR3/DR7, one assuming that the susceptibility gene for coeliac disease linked to DR alleles is a dominant one and the other that it is a recessive gene. The findings contradict the dominant model and fit the recessive one. These authors correctly pointed out that their model should be applicable when the expected and observed numbers of homozygous DR3/DR3 and DR7/DR7 were similar. These data, however, were not available to them. Our present study (Table 5) shows a deficit of homozygotes for DR3/DR3, DR7/DR7, DR5/DR5, and an excess of DR3/DR7 and DR7/DR5, which makes a model based on one recessive susceptibility gene unlikely.

At this stage there seems to be no obvious explanation of these findings. Several possibilities should be investigated: (a) One possibility is that simple hereditary models with one susceptibility gene within the HLA-DR region, recessive or dominant, cannot explain the mode of inheritance of coeliac disease. In that case, more complicated models with more than one susceptibility gene linked to the HLA-DR region (two dominant genes, two recessive genes, one dominant and one recessive gene) should be investigated. As DeMarchi $e a^{8} l^{8}$ have suggested, the susceptibility to coeliac disease might be determined by two genes within the HLA region, one in common with organ specific autoimmune diseases and in linkage disequilibrium with DR3, the other possibly specific for coeliac disease and associated with DR7. (b) It is also conceivable that our group of patients is not completely representative of the population of coeliacs, and that we failed to diagnose some of them because of the heterogeneity of the disease. The HLA-DR phenotypes of the coeliac patients might partially determine the mode of expression of the disease. For instance, it has been shown that when challenged with gluten coeliac children homozygous for HLA-DR3 display a more rapid 
and stronger response both clinically and histologically, as shown by small intestine biopsy specimens. ${ }^{16}$ Similarly, we have found that breast feeding delays the onset of symptoms in coeliac children with certain HLA-DR phenotypes. ${ }^{17}$ On the other hand, it is known that coeliac disease can coexist with a number of autoimmune diseases, most of them related to HLA-DR3. ${ }^{18-20}$ It seems possible that some of the HLA-DR3 homozygous patients are treated for some of these autoimmune diseases and are never diagnosed as having coeliac disease.

The absence of HLA-DR7 homozygotes in our series might be the result of a milder expression of the disease, because in less strongly affected patients a small intestinal biopsy is rarely performed. Another possible relevant point is that the present study, like most of those in which a relationship was found between coeliac disease and phenotype DR3/ DR7, ${ }^{81011}$ was performed in children and, furthermore, from Southern Europe or Israel. It would be of interest to determine whether the association of coeliac disease with phenotypes DR3/DR7 and DR7/DR5 is a sign of the heterogeneity of the disease in relation to the patients' age or their geographic origin. A study of this kind done in adult French coeliac patients, however, also shows an association with phenotype HLA-DR3/HLA-DR7. ${ }^{9}$ If heterogeneity of coeliac disease was actually related to the HLA-DR phenotype of the patients, each of the subgroups of coeliac disease might prove to have a specific mode of inheritance, as recently suggested by Rotter ${ }^{21}$ for insulin dependent diabetes mellitus. (c) Finally, for a better understanding of the inheritance of coeliac disease we must not forget the important role that other factors - both hereditary (apart from the factors within the HLADR region) and environmental - can play in the expression of the disease. This is illustrated by the discrepancy between the degree of concordance for coeliac disease among identical twins (in our series $50 \%$, in other series up to $70 \%{ }^{22}$ ) and the $29 \%$ seen in coeliac children's siblings who share their HLADR phenotypes with the propositus and have coeliac disease (in our series eight out of 31). These findings indicate that there is around $28 \%$ (50-29) chance that hereditary factors not coded by HLA are involved in gluten sensitive enteropathy. Some of these factors have been explored elsewhere. ${ }^{23}$ Greenberg and Rotter ${ }^{24}$ have proposed that the mode of inheritance of coeliac disease can be explained by two recessive loci one within and one outside the HLA region. The discrepancy with respect to coeliac disease among identical twins shows clearly that a number of environmental factors - for example, age at first exposure to gluten, amount of gluten ingested, presence or absence of breast-feeding, intercurrent infections - play a role in the expression of the disease.

There can be no doubt from the present results that the complexity of the genetics of coeliac disease equals that found for juvenile insulin-dependent diabetes mellitus (IDDM) ${ }^{25}$ In both diseases the number of homozygotes (DR3/DR3, DR4/DR4 for IDDM; DR3/DR3, DR7/DR7 for coeliac disease) is considerably smaller than the number of compound heterozygotes (DR3/DR4 for IDDM, DR3/DR7 for coeliac disease), and in both excess of haplotypesharing by affected sib pairs has been found in multiple case families where all members were HLA-typed. Furthermore, in studies on HLA- and GLO-typed families with IDDM the susceptibility gene proved to be located closer to HLA-DR than to GLO. ${ }^{26}$ The mode of inheritance of both diseases is still poorly understood. For coeliac disease, a model with one dominant susceptibility gene linked to the HLA-DR region seems very unlikely on the basis of the available data. The question whether one recessive susceptibility HLA-DR-linked gene can explain the hereditary pattern or a more complicated model is needed, deserves further clinical and experimental investigation. One important point concerns the possible heterogeneity of coeliac disease with respect to the HLA-DR phenotypes of the patients. We think that random HLA-DR and non-DR typing studies in coeliac patients differing as to age and ethnic and geographical origin will help to elucidate the still obscure aspects of the mode of inheritance of coeliac disease.

During this investigation one of us (M L Mearin) was supported by a grant from the Plan de Formación de Personal Investigador of the Spanish Ministry of Education. We would like to thank Professor $\mathrm{J} \mathrm{H}$ Edwards from the University of Oxford, England for valuable advice, and are grateful to Miss G W M Verhoef and Mrs L Steenhoff-Bosma for typing the manuscript, and Mrs I Seeger for reading the text.

\section{References}

1 Stokes PL, Asquith P, Holmes GKJ, McKintosh P, Cooke WT. Histocompatibility antigens associated with adult coeliac disease. Lancet 1972; 2: 162-4.

2 Falchuck ZM, Rogentine GN, Strober W. Predominance of histocompatibility antigen HLA-B8 in patients with gluten sensitive enteropathy. J Clin Invest 1972; 51: 1602-6.

3 Keuning JJ, Peña AS, van Leeuwen A, van Hoff JP, van Rood JJ. HLA-Dw3 associated with coeliac disease. Lancet 1976; 1: 506-8. 
4 Ek J, Albrechtsen D, Solheim BG, Thorsby E. Strong association between the HLA-Dw3 related B alloantigen DRw3 and coeliac disease. Scand $J$ Gastroenterol 1978; 13: 229-43.

5 Peña AS, Biemond I, Rosekrans PCM, van Leeuwen A, Schreuder I, van Rood JJ. DR locus controlled B-cell alloantigens in coeliac disease in The Netherlands. In: McConnell RB, ed. Genetics of coeliac disease. Liverpool: MTP Press, 1981; 161-71.

6 McKenna R, Stevens FM, Bourke M, McNicholl B, Albert ED, McCarthy CF. B-cell alloantigens associated with coeliac disease in the west of Ireland. In: McConnell RB, ed. Genetics of coeliac disease. Liverpool: MTP Press, 1981; 153-8.

7 Albert E, Harms K, Bertele R, et al. B-cell alloantigens in coeliac disease. In: McNicholl B, McCarthy DF, Fortrell PF, eds. Perspectives in coeliac disease. Lancaster: MTP Press, 1978; 123-9.

8 DeMarchi M, Borelli Y, Olivetti E, et al. Two- HLA-D and DR alleles are associated with coeliac disease. Tissue Antigens 1979; 14: 309-16.

9 Betuel H, Gebuhrer L, Descos L, Percebois H, Minaire Y, Bertrand J. Adult coeliac disease associated with HLA-DRw3 and DRw7. Tissue Antigens 1980; 15: 231-9.

10 Polanco I, Biemond I, van Leeuwen A, et al. Glutensensitive enteropathy in Spain: genetic and environmental factors. In: McConnell RB, ed. Genetics of coeliac disease. Liverpool: MTP Press, 1981; 211-34.

11 Brautbar C, Freier S, AshKenazi A, et al. Histocompatability determinants in Israeli Jewish patients with coeliac disease: population and family study. Tissue Antigens 1982; 17: 313-22.

12 Meeuwisse GW. Diagnostic criteria in coeliac disease. Acta Paediatr Scand 1970; 59: 461-3.

13 van Rood JJ, Ploem JS. Simultaneous detection of the two cell population by two-colour fluorescence and application to the recognition of B-cell determinants. Nature 1976; 262: 795-6.

14 Baur MP, Danilovs JA. Population analysis of HLA-A,
$-B,-C, D R$ and other genetic markers. In: Teresaki PI, ed. Histocompatibility testing 1980. Los Angeles: UCLA Tissue Typing Laboratory, 1980: 955-93.

15 Greenberg DA, Hodge SE, Rotter JI. Evidence for recessive, and against dominant inheritance at the HLA "linked" locus in coeliac disease. Am J Hum Genet 1982; 34: 263-77.

16 Polanco I. Factores Geneticos y ambientales de la enfermedad celiaca. University of Madrid: Thesis, 1980.

17 Polanco I, Vazquez C, Prieto G, et al. Coeliac disease: influence of breast feeding and HLA-DR phenotypes on the age of onset of symptoms. (Abstract.) Paediatr Res 1982; 16: 1043A.

18 Pittman FE, Holub DA. Sjörgren's syndrome and adult coeliac disease. Gastroenterology 1965; 48: (6) 869-76.

19 Cooper BT, Holmes GKJ Cooke WT. Coeliac disease and immunological disorders. $\mathrm{Br}$ Med J 1978; 1: 537-9.

20 Logan RFA, Ferguson A, Fiu Fayson NDC, Weir DO. Primary biliary cirrhosis and coeliac disease. Lancet 1978; 4: 230-3.

21 Rotter JI. The modes of inheritance of insulindependent diabetes mellitus. Am J Hum Genet 1981; 33: 835-51.

22 Peña AS. Genetics of coeliac disease. In: Jewell DP, Lee E, eds. Topics in Gastroenterology. Oxford: Blackwell, 1982; 62-81.

23 Peña AS, Mann DL, Hague NE, et al. Genetic basis of gluten-sensitive enteropathy. Gastroenterology 1978; 75: $230-5$

24 Greenberg DA, Rotter JI. Two locus model for gluten sensitive enteropathy: population genetic considerations. Am J Med Genet 1981; 8: 205-14.

25 Svejgaard A, Ryder LP. HLA genotype distribution and genetic models of insulin-dependent diabetes mellitus. Am J Hum Genet 1981; 45: 293-8.

26 Rubinstein P, Ginsberg-Fellner F, Falk C. Genetics of type I diabetes mellitus: a single, recessive predisposition gene mapping between HLA-B and GLO. Am J Hum Genet 1981; 33: 865-72. 